\title{
Efecto de harina de hidrolizado de vísceras en el crecimiento de trucha arcoíris (Oncorhynchus mykiss)
}

\author{
Jorge López-Macías ${ }^{1 * \otimes(0)}$ Dr.Sc; Julbrinner Salas-Benavides ${ }^{\circledR(10}$ M.Sc.
}

\begin{abstract}
${ }^{1}$ Universidad de Nariño, Facultad de Ciencias Pecuarias. Departamento de Recursos Hidrobiológicos, Grupo de Investigaciones en Acuacultura - GIAC, Pasto, Colombia.

¿Universidad del Tolima, Facultad de Ingeniería Agronómica. Doctorado en Ciencias Agrarias, Ibagué, Colombia.

*Correspondencia: jorgelopezmacias@gmail.com
\end{abstract}

Recibido: Abril 2020; Aceptado: Agosto 2020; Publicado: Noviembre 2020.

\section{RESUMEN}

Objetivo. Evaluar el efecto de la inclusión de la harina de hidrolizado de vísceras, en dietas para alevines de trucha variedad "Kamloop", en términos de ganancias de peso, talla, biomasa, conversión alimenticia aparente y sobrevivencia. Materiales y métodos. El ensayo, se desarrolló en el Centro Ambiental y Piscícola Guirapungo - Corponariño, en ocho piletas de concreto, subdivididas en tres compartimentos de iguales dimensiones. Se utilizó un Diseño Irrestrictamente al Azar (DIA), conformado por 1680 alevines de trucha, con un peso promedio de siembra de $1.24 \pm 0.024 \mathrm{~g}$, distribuidos en cuatro tratamientos, seis réplicas por tratamiento, para un total de 24 unidades experimentales, con 70 peces por unidad experimental y 420 peces por tratamiento. Resultados. El tratamiento 4, (dieta con $20 \%$ de hidrolizado de vísceras) registró con significancia estadística ( $\leq \leq 0.005)$ las mejores ganancias de peso, talla, biomasa, conversión alimenticia aparente y sobrevivencia promedio. En contraste, el tratamiento T1 (dieta comercial) reportó las variables productivas menos adecuadas. Conclusiones. La incorporación de hidrolizados de vísceras de peces, como fuente proteica en dietas balanceadas de trucha arcoíris, mejoran las variables zootécnicas de la producción piscícola, debido al valor biológico de las dietas que contiene el hidrolizado.

Palabras clave: Conversión alimenticia; ganancia de peso; dieta; proteína; variables productivas (Fuentes: DeCS, FAO).

\section{ABSTRACT}

Objective. To assess the effect of the inclusion of viscera hydrolyzate meal in diets for trout fry, "Kamloop" variety, in terms of weight, length and biomass gains, apparent feed conversion, and survival. Materials and methods. This essay was developed at the Guirapungo - Corponariño Environmental and Fish Farming Center, in eight concrete pools, subdivided each pool, into three compartments of equal dimensions. An Unrestricted Random Design (URD) was used, made up of 1680 trout fry, with an average stocking weight of $1.24 \pm 0.024 \mathrm{~g}$, distributed in four treatments, six replications per treatment, for a total of 24 units experimental, with 70 fish per experimental unit 
and 420 fish per treatment. Results. Treatment 4, (diet with $20 \%$ viscera hydrolyzed) recorded the greatest weight, length and biomass gains, the best feed conversion and average survival. In contrast, the T1 treatment (commercial feed) reported the least adequate productive variables. Conclusions. The incorporation of fish viscera hydrolysate, as a protein source in balanced diets of rainbow trout, improve the zootechnical variables of fish production, due to the biological value of the diets that the hydrolyzate contains.

Keywords: Feed conversion; weight gain; diet; protein; production variables (Sources: MeSH, FAO).

\section{INTRODUCCIÓN}

La acuicultura ha alcanzado gran importancia dentro del sistema alimentario, debido a la producción de bienes de gran calidad biológica, desde el punto de vista nutricional y a su ubicación en áreas deprimidas o de mediano desarrollo, donde puede originar una serie de actividades conexas que estimulan una dinámica de crecimiento, lo cual se hace mucho más evidente si se tiene en cuenta que el sistema alimentario colombiano, presenta limitaciones estructurales. En 2016, la producción pesquera mundial fue estimada en 171 millones de toneladas, de las cuales la acuicultura representó el $47 \%$ del total. Entre 1961 y 2016 , el aumento anual medio del consumo mundial de pescado, excluyendo el uso no alimentario, (3.2\%) superó al crecimiento de la población (1.6\%) y también al de la carne procedente de todos los animales terrestres juntos (2.8\%). En términos per cápita, el consumo de pescado comestible aumentó de $9.0 \mathrm{~kg}$ en 1961 a $20.2 \mathrm{~kg}$ en 2015, a una tasa media de aproximadamente un $1.5 \%$ al año, además de una proyección relativa a los años 2016 y 2017 hasta alcanzar $20.3 \mathrm{~kg}$ y $20.5 \mathrm{~kg}$, respectivamente (1).

En consecuencia, la importancia de la acuicultura es cada vez más reconocida, sobre todo en el abastecimiento de pescado como alimento de consumo humano, debido a que representa alrededor del $17 \%$ de la proteína animal consumida por la población mundial. Además, el pescado proporcionó casi un $20 \%$ del aporte medio de proteínas animales per cápita, a unos 3200 millones de personas (1). El departamento de Nariño, por ser fronterizo, andino, amazónico y pacífico, presenta condiciones excepcionales para el desarrollo de la acuicultura por su variedad de suelos, topografía, pisos térmicos cultivos y riqueza hídrica e ictiológica (2). Infortunadamente, las investigaciones realizadas en especies ícticas nativas de aguas frías del suroccidente colombiano, como el Eremophilus mutisii, han demostrado que este pez, no posee características ideales para el cultivo en piscicultura, debido a sus bajas ganancias diarias de peso, en condiciones de cautiverio, territorialidad, falta de rusticidad y la inmadurez del aparato digestivo, en la fase de postlarva, lo que obliga necesariamente a la producción a alto costo de alimento vivo específico (3).

Esta situación ha estimulado la explotación en las regiones frías de Nariño, de la especie foránea, trucha arcoíris (O. mykiss), sin que exista investigación previa que permita la implementación de paquetes tecnológicos rentables de alimentación, cultivo y reproducción de la mencionada especie íctica, que puedan ser transferidos y adaptados a las explotaciones existentes en los lagos interandinos de altura (4).

Las investigaciones realizadas por el Grupo de Investigaciones en Acuicultura de la Universidad de Nariño - GIAC, han demostrado que el cultivo de trucha arcoíris, es una alternativa viable de desarrollo socioeconómico para los campesinos localizados en las zonas frías del departamento de Nariño y específicamente en los lagos de altiplano Cumbal y La Cocha y sus respectivas cuencas $(5,6)$. En consecuencia, esta investigación se propuso evaluar la harina de hidrolizado de vísceras, en la formulación de dietas para truchas y su efecto sobre distintas variables productivas, durante la etapa de alevinaje y levante.

\section{MATERIALES Y MÉTODOS}

Sitio de estudio. La investigación se realizó en el Centro Ambiental y Piscícola Guirapungo, adscrito a Corponariño, localizado en el corregimiento El Encano, lago Guamuez a una altura de 2.840 msnm, temperatura promedio del agua de $13^{\circ} \mathrm{C}$, con una extensión de 4.280 Has. Las coordenadas geográficas son: $01^{\circ} 06^{\prime} 3.80^{\prime \prime} \mathrm{N}$ y $77^{\circ} 07^{\prime} 2.26^{\prime \prime}$ W (7).

Período de estudio. La investigación se inició, una vez se dispuso del acuerdo de aprobación por parte del Comité de Ética de la Universidad de 
Nariño. El trabajo de campo se realizó de marzo de 2018, a abril de 2019, periodo en el cual, se efectuaron diferentes actividades previas como la adquisición y aclimatación de alevines, división de piletas, elaboración de dietas, estandarización de las técnicas de alimentación, adaptación y suministro de alimento. Finalmente se evaluó durante siete meses, el efecto de la harina de hidrolizado de vísceras, en las fases de cultivo. Para este efecto, se sembraron aleatoriamente en los distintos tratamientos, 1680 alevines de trucha variedad "Kamloop" con un peso promedio inicial de $1.24 \pm 0.024 \mathrm{~g}$, longitud total promedio de $4.26 \pm 0.824 \mathrm{~cm}$. Los anteriores valores, no registraron diferencias estadísticas en los respectivos tratamientos $(p>0.05)$.

Instalaciones. El proyecto se desarrolló en ocho piletas de concreto de $2.70 \mathrm{~m}$ de largo, $1 \mathrm{~m}$ de ancho y $0.65 \mathrm{~m}$ de columna de agua, subdividida cada pileta, mediante marcos de madera y angeo, en tres compartimentos iguales de $0.90 \mathrm{~m}$ (Figura 1).

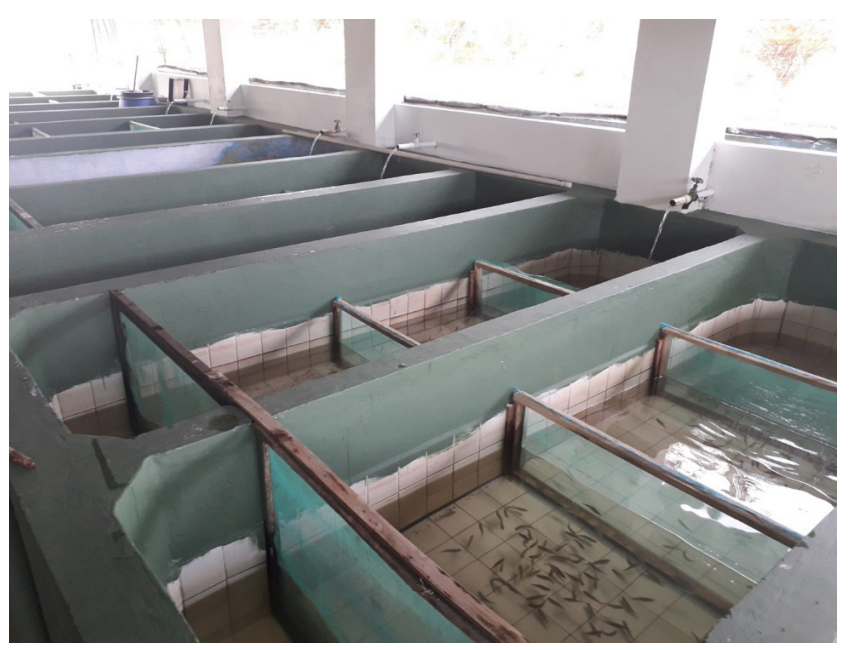

Figura 1. Unidades experimentales.

Limpieza de piletas. Antes de la siembra de los ejemplares, se lavaron las piletas, con agua y solución comercial de hipoclorito de sodio al $2 \%$, con el propósito de evitar la presencia de posibles agentes patógenos.

Aclimatación de ejemplares. Una vez se recibieron los alevines de trucha arcoíris, se ejecutó el proceso de adaptación, con este propósito se dejaron flotar en la superficie del agua, las bolsas plásticas que contenían los peces durante 30 minutos, para equilibrar temperaturas. Pasado este tiempo, se adicionó agua de las piletas a las bolsas, hasta lograr homogenizar las temperaturas y posteriormente se realizó la siembra.

Monitoreo de los parámetros fisicoquímicos. Se registraron cada tres días, durante todo el período experimental a las $3 \mathrm{pm}$, la temperatura, oxígeno y pH del agua, mediante un Kit de campo para análisis de agua, marca $\mathrm{HACH}$ referencia FF - $1^{\text {a }}$ (Hach, Loveland, CO).

Muestreos. Se efectuaron censos en la siembra $y$ en la finalización del experimento y cinco muestreos mensuales, que consistieron en la captura del $15 \%$ de la población total de cada unidad experimental. No se proporcionó alimento, el día del muestreo con el fin de reducir la actividad metabólica y su efecto negativo en el pesaje. Los ejemplares, se capturaron mediante nasas de pesca y baldes, manteniendo durante el proceso de muestreo, todos los protocolos de bienestar animal, reduciendo el estrés al máximo, mediante aireación permanente y sedación leve con una solución comercial al $0.5 \%$ a base de clavo de olor. Para el registro de talla y peso se utilizó respectivamente un ictiómetro de madera y una balanza electrónica con sensibilidad 0.001 g (OHAUS, Parsippany, NJ) La información se consignó en una base de datos, lo cual permitió calcular la biomasa y la cantidad de alimento a suministrar en la semana siguiente.

Profilaxis. Los ejemplares fueron sometidos a baños de inmersión con una solución comercial de $\mathrm{NaCl}$ a dosis de $5 \mathrm{~g} / \mathrm{L}$. Este proceso se realizó cada dos semanas en baldes de $12 \mathrm{~L}$ por un lapso de 10 minutos y después de las labores de cada muestreo, con el fin de mejorar la permeabilidad osmótica de las branquias y disminuir la mortalidad. Las paredes de las piletas se lavaban y cepillaban cada dos semanas, para evitar agentes patógenos que pudieran afectar a los ejemplares.

Preparación del hidrolizado. El hidrolizado se elaboró a partir de $50 \mathrm{~kg}$ de vísceras, a las cuales se les eliminó el tejido graso, contenido gastrointestinal y la vesícula biliar Una vez terminado el proceso de limpieza, se procedió a licuar las vísceras, hasta obtener una pasta homogénea, la cual se llevó a cocción durante 10 minutos en una estufa hasta alcanzar $80^{\circ} \mathrm{C}$ y se dejó enfriar a temperatura ambiente. Se adicionó $2 \%$ de ácido sulfúrico de $98 \%$ de pureza, y $5 \%$ de melaza. El pH del hidrolizado se evaluó a las 24, 48 y 72 horas, después de preparado, hasta obtener un $\mathrm{pH}$ constante de $3.0 \pm 0.2$, con el propósito de mantener las condiciones ideales para la ruptura de las cadenas peptídicas 
y control sobre el crecimiento bacteriano. El hidrolizado se llevó a un autoclave eléctrico de vapor a presión, de $25 \mathrm{~L}$ de capacidad a $90^{\circ} \mathrm{C}$ durante 10 minutos (All American, Manitowoc, WI) y luego se almacenó en recipientes plásticos, con tapa de $10 \mathrm{~L}$ de capacidad, debidamente rotulados, y mantenidos a temperatura ambiente y en total oscuridad, por un periodo de 20 días. Se realizó un monitoreo constante durante dicho periodo, mezclando dos veces al día el contenido del recipiente y manteniendo limpia las paredes libres del mismo, mediante el uso de un paño ligeramente humedecido con una solución comercial de hipoclorito de sodio al $2 \%$, para evitar la contaminación bacteriana. Posteriormente se vertió el hidrolizado en bandejas de acero inoxidable hasta formar una capa de $4 \mathrm{~mm}$ de espesor, secando a una temperatura de $60^{\circ} \mathrm{C}$ en un horno (Memmert, Schwabach, Germany) por un tiempo de 14 horas hasta obtener una pasta dura, finalmente se llevó a un micro molino (IKA, Staufen, Germany) para obtener su harina.

Tamizaje y análisis bromatológico de materias primas. Las distintas materias primas seleccionadas, en las dietas experimentales, fueron molidas y tamizadas a un tamaño de partícula de 450 u para facilitar la homogenización, luego se les realizó un análisis proximal y energético, siguiendo la metodología de AOAC (8), adaptado por el Laboratorio de Bromatología de Laboratorios Especializados de la Universidad de Nariño.

Elaboración de las dietas. Se utilizó una dieta comercial, sin pigmento con $48 \%$ de proteína como tratamiento testigo, comparado con dietas experimentales isoproteicas $(45.17 \pm 0.15)$ e isoenergéticas (4066.90 28.75$)$, elaboradas con diferentes porcentajes de harina de hidrolizado de vísceras, como fuente de proteína animal, mezcladas con otras materias primas vegetales de uso común en peces, aceite de pescado como fuente lipídica animal y una premezcla comercial vitamínica y mineral (Tabla 1). Las dietas fueron suministradas durante las etapas de alevinaje y levante, de acuerdo con las necesidades nutricionales de la trucha arcoíris.

Balanceo de las dietas. El balanceo de las dietas experimentales, isoproteicas e isoenergéticas, se realizó mediante el programa comercial Feedsoft Enterprise (2018) y la herramienta Solver de Excel (2018), cuantificando los aportes nutritivos, en base parcialmente seca de cada materia prima utilizada, según los análisis bromatológicos certificados realizados por la sección de Laboratorios Especializados de la Universidad de Nariño, en lo referente a materia seca, ceniza, extracto etéreo, fibra cruda, proteína, extracto no nitrogenado y energía bruta.

Porcentaje de alimentación. El alimento se suministró "ad libitum" iniciando al 10\% promedio del peso vivo diariamente (P.V.D), un mes después se redujo al $8 \% ; 7 \%$ al tercer muestreo; $6 \%$ al cuarto muestreo; $5 \%$ al quinto muestreo, $4 \%$ del P.V.D al sexto muestreo, hasta la finalización del ensayo, con el propósito de asegurar un adecuado consumo de las dietas experimentales, el cual, se estableció suministrando el alimento en los porcentajes anteriormente señalados y retirando mediante sifoneo el alimento no consumido. Posteriormente, el material colectado no consumido, se secaba a temperatura ambiente, en bandejas de plástico, luego se pesaba por réplica y tratamiento y se determinaba de esta manera el consumo real. La distribución del alimento se efectuó siete días a la semana, con excepción de los días de muestreo, fraccionado en seis comidas por día, en los cuatro primeros meses y cuatro comidas en los tres meses restantes.

Tratamientos. Se evaluaron cuatro tratamientos, seis réplicas por tratamiento, para un total de 24 unidades experimentales, con 70 peces por unidad experimental y 420 peces por tratamiento, para un total de 1680 peces con un peso promedio de siembra de los ejemplares de $1.24 \pm 0.024 \mathrm{~g}$, el cual no registró diferencias estadísticas $(p>0.05)$. Los tratamientos se distribuyeron en la siguiente forma:

T1: Balanceado comercial sin hidrolizado de vísceras.

T2: Balanceado experimental con $10 \%$.de hidrolizado de vísceras.

T3: Balanceado experimental con $15 \%$.de hidrolizado de vísceras

T4: Balanceado experimental con $20 \%$.de hidrolizado de vísceras.

Diseño experimental. Se utilizó un Diseño Irrestrictamente al Azar (DIA), conformado por cuatro tratamientos y seis réplicas por tratamiento, para un total de 24 unidades experimentales. Los peces se sembraron de manera totalmente aleatoria. 
Tabla 1. Dietas experimentales mediante porcentajes de sustitución con vísceras de pescado.

\begin{tabular}{|c|c|c|c|c|c|c|c|c|c|c|c|}
\hline 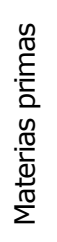 & 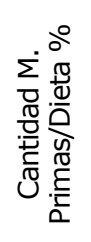 & 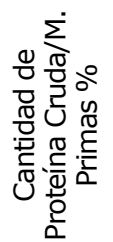 & 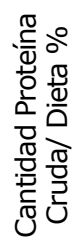 & 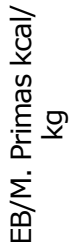 & 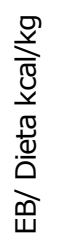 & 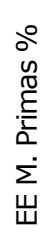 & 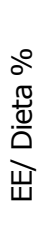 & 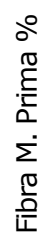 & 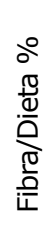 & 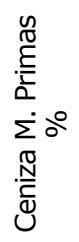 & 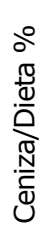 \\
\hline
\end{tabular}

\begin{tabular}{|c|c|c|c|c|c|c|c|c|c|c|c|c|}
\hline \multicolumn{13}{|c|}{ Dieta experimental 1: 10\% Hidrolizado de vísceras de trucha. Relación energía - proteína 8.94. } \\
\hline Harina de carne & 29.5 & 70.88 & 20.9 & 5410 & 1596 & 16 & 4.72 & 1.18 & 0.35 & 3.61 & 1.06 & 8.33 \\
\hline Hidrolizado de vísceras & 10 & 60.4 & 6 & 5520 & 552 & 17.3 & 1.73 & 0.35 & 0.04 & 6.47 & 0.65 & 15.48 \\
\hline Torta de soya & 25.5 & 42.5 & 10.8 & 2095 & 534.2 & 4.8 & 1.22 & 5.9 & 1.5 & 7.25 & 1.85 & 39.55 \\
\hline Harina de Maíz & 27.9 & 7.08 & 7.08 & 3790 & 1057.4 & 1.85 & 0.52 & 9.28 & 2.59 & 0.48 & 0.13 & 81.31 \\
\hline Aceite de pescado & 2 & 3 & 0.1 & 1000 & 200 & 100 & 2 & 0 & 0 & 0 & 0 & 0 \\
\hline Melaza & 3 & 9.7 & 0.3 & 3390 & 101.7 & 0.9 & 0.03 & 6.3 & 0.189 & 12.5 & 0.38 & 70.6 \\
\hline $\begin{array}{l}\text { Premezcla vitaminas y } \\
\text { minerales }\end{array}$ & 2 & 0 & 0 & 0 & 0 & 0 & 0 & 0 & 0 & 0 & 0 & 0 \\
\hline Ácido ascórbico & 0.05 & 0 & 0 & 0 & 0 & 0 & 0 & 0 & 0 & 0 & 0 & 0 \\
\hline Oxitetraciclina & 0.05 & 0 & 0 & 0 & 0 & 0 & 0 & 0 & 0 & 0 & 0 & 0 \\
\hline Requerimiento & 100 & & 45.2 & & 4041.3 & & 10.2 & & 4.67 & & 4.07 & \\
\hline \multicolumn{13}{|c|}{ Dieta experimental 2: 15\% Hidrolizado de vísceras de trucha. Relación energía - proteína 8.96. } \\
\hline Harina de carne & 25.4 & 70.88 & 18 & 5410 & 1374.1 & 16 & 4.064 & 1.18 & 0.3 & 3.61 & 0.92 & 8.33 \\
\hline Hidrolizado de vísceras & 15 & 60.4 & 9.1 & 5520 & 828 & 17.3 & 2.6 & 0.35 & 0.05 & 6.47 & 0.97 & 15.5 \\
\hline Torta de soya & 25.5 & 42.5 & 10.8 & 2095 & 534.2 & 4.8 & 1.22 & 5.9 & 1.5 & 7.25 & 1.85 & 39.55 \\
\hline Harina de Maíz & 27 & 7.08 & 7.08 & 3790 & 1023.3 & 1.85 & 0.5 & 9.28 & 2.51 & 0.48 & 0.13 & 81.31 \\
\hline Aceite de pescado & 2 & 3 & 0.1 & 10000 & 200 & 100 & 2 & 0 & 0 & 0 & 0 & 0 \\
\hline Melaza & 3 & 9.7 & 0.3 & 3390 & 101.7 & 0.9 & 0.03 & 6.3 & 0.189 & 12.5 & 0.38 & 70.6 \\
\hline $\begin{array}{c}\text { Premezcla vitaminas y } \\
\text { minerales }\end{array}$ & 2 & 0 & 0 & 0 & 0 & 0 & 0 & 0 & 0 & 0 & 0 & 0 \\
\hline Ácido ascórbico & 0.05 & 0 & 0 & 0 & 0 & 0 & 0 & 0 & 0 & 0 & 0 & 0 \\
\hline Oxitetraciclina & 0.05 & 0 & 0 & 0 & 0 & 0 & 0 & 0 & 0 & 0 & 0 & 0 \\
\hline Requerimiento & 100 & & 45.3 & & 4061.4 & & 10.41 & & 4.55 & & 4.24 & \\
\hline \multicolumn{13}{|c|}{ Dieta experimental 3: $20 \%$ Hidrolizado de vísceras de trucha. Relación energía - proteína 9.11. } \\
\hline Harina de carne & 22.7 & 70.88 & 16.1 & 5410 & 1228.1 & 16 & 3.632 & 1.18 & 0.27 & 3.61 & 0.82 & 8.33 \\
\hline Hidrolizado de vísceras & 20 & 60.4 & 12.1 & 5520 & 1104 & 17.3 & 3.46 & 0.35 & 0.07 & 6.47 & 1.29 & 15.48 \\
\hline Torta de soya & 22.2 & 42.5 & 9.4 & 2095 & 465.1 & 4,8 & 1.07 & 5.9 & 1.31 & 7.25 & 1.61 & 39.55 \\
\hline Harina de Maíz & 29 & 7.08 & 7.08 & 3790 & 1099.1 & 1.85 & 0.54 & 9.28 & 2.69 & 0.48 & 0.14 & 81.31 \\
\hline Aceite de pescado & 1 & 3 & 0 & 10000 & 100 & 100 & 1 & 0 & 0 & 0 & 0 & 0 \\
\hline Melaza & 3 & 9.7 & 0.3 & 3390 & 101.7 & 0.9 & 0.027 & 6.3 & 0.189 & 12.5 & 0.38 & 70.6 \\
\hline $\begin{array}{c}\text { Premezcla vitaminas y } \\
\text { minerales }\end{array}$ & 2 & 0 & 0 & 0 & 0 & 0 & 0 & 0 & 0 & 0 & 0 & 0 \\
\hline Ácido ascórbico & 0.05 & 0 & 0 & 0 & 0 & 0 & 0 & 0 & 0 & 0 & 0 & 0 \\
\hline Oxitetraciclina & 0.05 & 0 & 0 & 0 & 0 & 0 & 0 & 0 & 0 & 0 & 0 & 0 \\
\hline Requerimiento & 100 & & 45 & & 4098 & & 9.72 & & 4.53 & & 4.24 & \\
\hline
\end{tabular}

$\mathrm{EB}=$ Energía bruta. $\mathrm{EE}=$ Extracto etéreo. $\mathrm{ENN}=$ Extracto no nitrogenado.

Con el software estadístico SPSS IBM 20, se efectuó un análisis de varianza (ANDEVA) para determinar las diferencias estadísticas significativas entre los tratamientos y en aquellas variables que registraron diferencias estadísticas, se aplicó la prueba de comparación múltiple de Tuckey al 95\% de confiabilidad. Con el propósito de establecer el mejor tratamiento con respecto a ganancias de peso, talla, biomasa y conversión alimenticia. 


\section{Variables evaluadas}

Ganancia de peso (GP). Se define como el incremento de peso de la población, en un periodo determinado de tiempo.

Ganancia de talla (GT). Se define como el incremento en talla de la población, en un periodo determinado de tiempo.

Ganancia de Biomasa (GB). Es el peso total de peces producidos en cada tratamiento.

Conversión alimenticia aparente (C.a.a). Es la relación entre el alimento suministrado y el incremento de peso obtenido durante el período experimental.

Sobrevivencia (S). Corresponde al porcentaje de animales que sobreviven al final del periodo experimental.

\section{RESULTADOS}

Ganancia de peso: Las ganancias de peso diario, peso a los 120 días y peso al final del experimento presentaron diferencias significativas entre tratamientos $(p \leq 0.01)$. La prueba de Tukey demostró que el T4 al mes 7, registró la mayor ganancia de peso (203.17 \pm 8.15$)$, mientras que

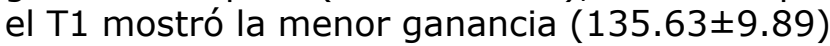
(Tabla 2).

Tabla 2. Ganancia de peso diario, ganancia de peso a los 120 días y ganancia de peso final expresados en gramos.

\begin{tabular}{|c|c|c|c|}
\hline Tratamiento & GDP $\mathbf{g}$ & GD $\mathbf{g}$ & GPF $\mathbf{g}$ \\
\hline $\mathrm{T} 1$ & $\begin{array}{l}0.6467 \mathrm{~d} \\
\pm 0.472\end{array}$ & $\begin{array}{l}17.77^{d} \\
\pm 1.02\end{array}$ & $\begin{array}{c}135.63^{d} \\
\pm 9.89\end{array}$ \\
\hline $\mathrm{T} 2$ & $\begin{array}{l}0.7234^{c} \\
\pm 0.401\end{array}$ & $\begin{array}{l}25.37 c \\
\pm 2.74\end{array}$ & $\begin{array}{c}151.90^{c} \\
\pm 8.42\end{array}$ \\
\hline T3 & $\begin{array}{l}0.8411^{b} \\
\pm 0.250\end{array}$ & $\begin{array}{l}27.13^{b} \\
\pm 1.61\end{array}$ & $\begin{array}{c}176.63^{b} \\
\pm 5.25\end{array}$ \\
\hline $\mathrm{T} 4$ & $\begin{array}{l}0.9675^{a} \\
\pm 0.388\end{array}$ & $\begin{array}{l}34.10^{\mathrm{a}} \\
\pm 1.25\end{array}$ & $\begin{array}{c}203.17^{a} \\
\pm 8.15\end{array}$ \\
\hline EEM & 0.00825 & 0.435 & ------- \\
\hline
\end{tabular}

GDP: ganancia de peso diario, GD: ganancia de peso a los 120 días (mes 4). GPF: ganancia de peso final expresados en gramos. Media \pm desviación estándar. EEM: error estándar de la media cuadrática. Letras diferentes por columna muestran diferencias estadísticas significativas $(p<0.05)$.
En el período experimental, El crecimiento promedio fue $146.1 \%$ en el tratamiento T4, con relación al $\mathrm{T} 1$; según el porcentaje de relación, en el mejor tratamiento, la mayor tasa de crecimiento se presentó en los cuatro primeros meses de evaluación equivalente a $2650 \%$ (1.24 a $17.77 \mathrm{~g})$; menor incremento se evidenció en los meses quinto a séptimo, equivalente a $496 \%$ (203.17 g).

Ganancia de talla. El análisis de varianza es significativo $(p \leq 0.01)$, para el crecimiento en talla, mes a mes de los ejemplares de cada tratamiento. En consecuencia, existe diferencia significativa entre los días del experimento, pero dependiendo del tipo de dieta, así, el incremento de talla mayor fue en T4 $(26.01 \pm 0.34 \mathrm{~cm})$; en contraste, la dieta 1 estableció la menor media $(21.02 \pm 1.35 \mathrm{~cm})$. La prueba Tukey por mes y tratamiento, demuestra el cambio cronológico de la media en el indicador de estudio (Tabla 3).

Tabla 3. Ganancia diaria de longitud, ganancia de longitud a los 120 días, ganancia de longitud final expresadas en centímetros.

\begin{tabular}{cccc}
\hline Tratamiento & GDL cm & GL cm & GLF cm \\
\hline \multirow{2}{*}{ T1 } & $0.100^{\mathrm{d}}$ & $13.53^{\mathrm{d}}$ & $21.02^{\mathrm{d}}$ \\
& \pm 0.0065 & \pm 0.61 & \pm 1.35 \\
T2 & $0.109^{\mathrm{c}}$ & $12.74^{\mathrm{c}}$ & $23.00^{\mathrm{c}}$ \\
& \pm 0.0032 & \pm 1.61 & \pm 0.66 \\
T3 & $0.113^{\mathrm{b}}$ & $12.93^{\mathrm{b}}$ & $23.80^{\mathrm{b}}$ \\
& \pm 0.0029 & \pm 0.46 & \pm 0.60 \\
T4 & $0.124^{\mathrm{a}}$ & $13.14^{\mathrm{a}}$ & $26.01^{\mathrm{a}}$ \\
& \pm 0.0017 & \pm 0.46 & \pm 0.34 \\
& 0.00061 & 0.065 & ------- \\
\hline
\end{tabular}

GDL: ganancia diaria de longitud, GD: ganancia de longitud a los 120 días (mes 4). GLF: ganancia de longitud final expresados en centímetros. Media \pm desviación estándar. EEM: error estándar de la media cuadrática. Letras diferentes por columna muestran diferencias estadísticas significativas $(p<0.05)$.

El incremento de talla, a través de los distintos muestreos, experimentó similar tendencia entre los tratamientos; durante los meses 1 a 4 (120 días de evaluación), el mejor tratamiento reveló mayor variación $(208 \%)$ y menor tasa de crecimiento durante el último trimestre de evaluación (98\%).

Ganancia de biomasa. En la tabla 4, se indica que la ANDEVA es significativa ( $p \leq 0.01)$, para el incremento mensual de biomasa. En 
consecuencia, existe diferencia significativa entre los días del experimento, dependiendo del tratamiento. En el mes siete, la dieta que marcó mayor media correspondió al tratamiento 4, (13376.49 $\pm 576.41 \mathrm{~g})$; mientras que T1 registró la menor media (7025.24 $\pm 1541.16 \mathrm{~g})$.

Tabla 4. Ganancia diaria de biomasa, ganancia de biomasa a los 120 días y ganancia de biomasa final expresada en gramos.

\begin{tabular}{cccc}
\hline Tratamiento & GDB g & GB g & GBFg \\
\hline T1 & $33.430^{\mathrm{d}}$ & $1161.65^{\mathrm{d}}$ & $7025.24^{\mathrm{d}}$ \\
& \pm 7.339 & \pm 69.90 & \pm 1541.16 \\
$\mathrm{~T} 2$ & $44.369^{\mathrm{c}}$ & $1704.39^{\mathrm{c}}$ & $9317.45^{\mathrm{c}}$ \\
& \pm 2.658 & \pm 185.55 & \pm 558.15 \\
$\mathrm{~T} 3$ & $53.970^{\mathrm{b}}$ & $1836.01^{\mathrm{b}}$ & $11333.65^{\mathrm{b}}$ \\
& \pm 1.818 & \pm 108.91 & \pm 381.77 \\
$\mathrm{~T} 4$ & $63.698^{\mathrm{a}}$ & $2335.78^{\mathrm{a}}$ & $13376.49^{\mathrm{a}}$ \\
& \pm 2.745 & \pm 85.87 & \pm 576.41 \\
EEM & 0.77612 & 37.79 & ------- \\
\hline
\end{tabular}

GDB: ganancia diaria de biomasa. GB: ganancia de biomasa a los 120 días (mes 4). GBF: ganancia de biomasa final expresada en gramos. Media \pm desviación estándar. EEM: error estándar de la media cuadrática. Letras diferentes por columna muestran diferencias estadísticas significativas $(p<0.05)$.

El peso total de peces producidos en el tratamiento 4, según el porcentaje de relación, reveló en el último trimestre un incremento de $473 \%$ en la biomasa cosechada.

Conversión alimenticia aparente. El análisis de varianza de la conversión alimenticia aparente es significativo $(p \leq 0.01)$ en el periodo de evaluación. En consecuencia, existe diferencia significativa entre los meses experimentales. La dieta menos adecuada, en esta variable fue T1, $(2.68 \pm 1.23)$, y la mejor conversión alimenticia

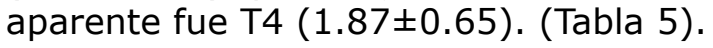

Tabla 5. Conversión alimenticia aparente diaria, conversión alimenticia aparente a los 120 días y conversión alimenticia aparente final.

\begin{tabular}{cccc}
\hline Tratamiento & CAD & CA & CAF \\
\hline T1 & $0.0255^{\mathrm{d}} \pm 0.118$ & $1.18^{\mathrm{d}} \pm 0.27$ & $2.68^{\mathrm{d}} \pm 1.23$ \\
T2 & $0.0222^{\mathrm{c}} \pm 0.009$ & $0.77^{\mathrm{c}} \pm 0.30$ & $2.33^{\mathrm{c}} \pm 0.93$ \\
T3 & $0.0240^{\mathrm{b}} \pm 0.009$ & $0.70^{\mathrm{b}} \pm 0.12$ & $2.52^{\mathrm{b}} \pm 0.98$ \\
T4 & $0.0178^{\mathrm{a}} \pm 0.006$ & $0.54^{\mathrm{a}} \pm 0.04$ & $1.87^{\mathrm{a}} \pm 0.65$ \\
EEM & 0.00062 & 0.035 & ------- \\
\hline
\end{tabular}

CAD: conversión alimenticia diaria. CA: conversión alimenticia a los 120 días (mes 4). CAF: conversión alimenticia final. Media \pm desviación estándar. EEM: error estándar de la media cuadrática. Letras diferentes por columna muestran diferencias estadísticas significativas $(p<0.05)$.
Sobrevivencia. El análisis de sobrevivencia de los ejemplares de trucha arcoíris en las dietas experimentales, definió diferencias significativas $(p=0.000)$, con mayor media en el tratamiento $4(94 \%)$, sin diferir de los tratamientos 2 y 3 , (respectivamente 88 y $92 \%$ ). En contraste la menor sobrevivencia se registró en el T1 (Figura 2).

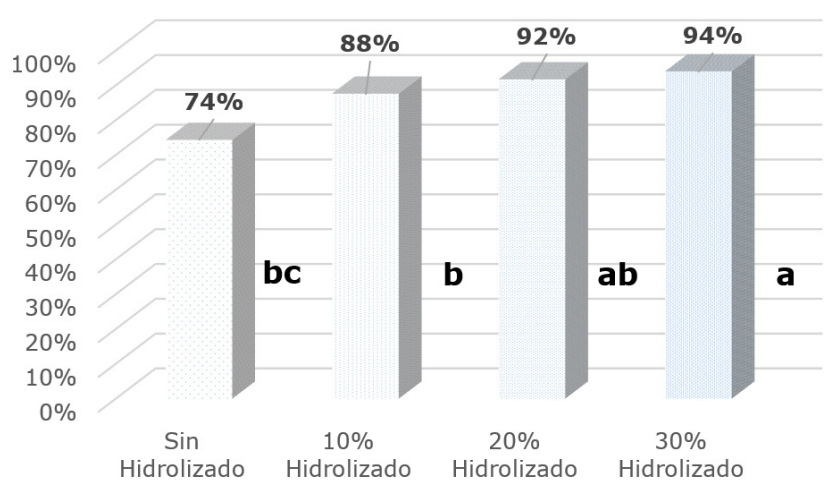

Figura 2. Porcentaje de sobrevivencia final, en los diferentes tratamientos experimentales.

Teniendo en cuenta todas las variables productivas, se estableció que el tratamiento 4 (dieta con $20 \%$ de hidrolizado de vísceras), presentó las mayores ganancias de peso (203.17 \pm 8.15$)$, longitud total $(26.01 \pm 0.34$ centímetros), biomasa (13376.49 $\pm 576.41 \mathrm{~g})$, conversión alimenticia ( $1.87 \pm 0.65$ unidades), sobrevivencia promedio ( $94 \%$ ); en comparación con el T1 (dieta comercial) que reportó las variables productivas menos adecuadas, con una conversión alimenticia de $2.68 \pm 1.23$.

Parámetros fisicoquímicos del agua. La temperatura promedio en las piletas, fue de $15.9^{\circ} \mathrm{C}$, una máxima de $16.2^{\circ} \mathrm{C}$ en época de menor precipitación y un valor menor de $15.7^{\circ} \mathrm{C}$ en período de lluvias. El coeficiente de relación señala que la máxima variación del parámetro se estimó en 1.03 (3.18\%) grados Celsius. El pH promedio en la investigación fue de 6.9 , con un mínimo de 6.2 y un máximo de 7.3. El coeficiente de relación señala que la máxima variación del parámetro se estimó en 1.17 (17\%) unidades de $\mathrm{pH}$. El oxígeno promedio en la investigación fue de 7.05, con un mínimo de 6.9 y un máximo de 7.23. El coeficiente de relación señala que la máxima variación del parámetro se estimó en $1.02(2.8 \%) \mathrm{mg} / \mathrm{L}$. 


\section{DISCUSIÓN}

Las especies ícticas cuando se levantan en recintos cerrados, como jaulas flotantes o estanques, deben consumir alimentos artificiales que aporten todos los nutrientes necesarios (carbohidratos, grasas, proteínas, fibra, vitaminas, minerales y agua), de acuerdo con las distintas etapas fisiológicas y condiciones de manejo (9). Sin embargo, las altas densidades de siembra que se trabaja en truchicultura, generan gran acumulación de metabolitos de desecho, causando estrés continuado que deprime el sistema inmunológico de los peces, haciéndolos más propensos al ataque de virus, parásitos, bacterias y hongos oportunistas, causando elevadas mortalidades, durante el período de cultivo. Por tanto, uno de los mecanismos para fortalecer el sistema inmunológico, es el suministro de alimentos artificiales elaborados con fuentes proteicas de excelente calidad, que proporcionen proteínas que aseguren la síntesis de anticuerpos, los cuales constituyen el mecanismo defensivo de los peces, reduciendo las tasas de mortalidad, acortando el tiempo de cultivo desde la siembra hasta la cosecha e incrementando por ende la rentabilidad de cada ciclo de producción (9). Infortunadamente la truchicultura colombiana, enfrenta actualmente un elevado costo de las materias primas proteicas tradicionales utilizadas, en la elaboración de balanceados para peces, debido a la escasez y alto costo en el mercado internacional de la harina de pescado, como fuente se proteína de alta calidad, afectando la rentabilidad del subsector piscícola (10); creándose así la necesidad de evaluar fuentes proteicas no tradicionales de bajo costo, como sería el caso de las harinas de hidrolizados obtenidos, a partir de subproductos acuícolas, los cuales poseen propiedades fisicoquímicas, bioactivas, funcionales y nutricionales con potencial de transferencia a los pequeños productores de trucha arcoíris y al mismo tiempo sean ecológicamente amigable con los ambientes prístinos circundantes al entorno lacustre piscícola de la región nariñense.
Por lo anteriormente expuesto, la incorporación de harina de hidrolizados de vísceras de peces, como fuente proteica en dietas balanceadas de trucha arcoíris, demuestra en esta investigación mejorar las variables zootécnicas de la producción piscícola, debido a la calidad biológica de las dietas. $(9,11)$, lo que se refleja finalmente en un mejor aprovechamiento de los nutrientes provenientes del hidrolizado y por ende mayores tasas de sobrevivencia, ganancias de peso y mejores conversiones alimenticias (9). Lo anterior coincide con Peréa et al (12), que alcanzaron mayor media (142.14 $\pm 4.74 \mathrm{~g}$ ) cuando alimentaron tilapias rojas utilizando $20 \%$ de hidrolizado de vísceras de trucha.

Durante el ensayo, también se observó que los peces presentaban mayor consumo de las dietas experimentales, con relación al alimento comercial, demostrando la mayor palatabilidad de las dietas con hidrolizado de vísceras (13).

En conclusión, la incorporación de $20 \%$ de harina de hidrolizados de vísceras de peces, como fuente proteica en dietas balanceadas de trucha arcoíris, mejoran las variables zootécnicas de la producción piscícola, debido a la calidad biológica de las dietas.

\section{Conflicto de intereses}

Los autores del presente estudio declaramos que no existe conflicto de intereses con la publicación de este manuscrito.

\section{Agradecimientos}

Vicerrectoría de Investigaciones, Posgrados y Relaciones Internacionales de la Universidad de Nariño, como financiador mediante convocatoria abierta docente de la presente investigación. Igualmente, los autores reconocen el apoyo logístico proporcionado por el Centro Ambiental y Piscícola Guirapungo, adscrito a Corponariño.

\section{REFERENCIAS}

1. FAO. El estado actual de la pesca y la acuicultura. Cumplir los objetivos de desarrollo sostenible. Departamento de pesca y acuicultura de la FAO, Organización de las naciones unidas para la alimentación y la agricultura. Roma: FAO; 2018. http:// www.fao.org/3/i9540es/i9540es.pdf
2. Acosta A, Ortega C, Sanguino W, Ceballos $B$, López J. Evaluación de tres tipos de alimento como dieta en post-larvas de sábalo amazónico (Brycon melanopterus, Cope 1872). Rev Vet Zootec. 2010; 1:4250. http://vetzootec.ucaldas.edu.co/ downloads/v4n1a06.pdf 
3. Bastidas J, Lemus C. Aporte al conocimiento de la biología y ecología del pez capitán de la sabana (Eremophilus mutisii). Humboldt 1805. (pisces: trichomycteridae) en el altiplano Cundiboyacense. 1ra. ed. Bogotá: Corporación Universitaria de Ciencia y Desarrollo UNICIENCIA; 2014. https://www. uniciencia.edu.co/images/documentos/ Investigacion/publicaciones/8-Pez-capitande-la-sabana.pdf

4. Salas J, López J. Caracterización comparativa de la condición limnológica del lago Guamuéz en relación con la producción de trucha arcoiris (Oncorhynchus mykiss) en jaulas flotantes, Rev Entornos. 2013; 26(2):181-199. https://doi.org/10.25054/01247905.483

5. López J, Salas J. Ortega A, Gómez V. Caracterización parasitaria de la trucha arcoíris (Oncorhynchus mykiss) y su efecto en la producción de la estación piscícola flotante Intiyaco, en el lago Guamuez (Nariño). Rev Veterinaria Zootecnía. 2014; 8(2):87101. http://vip.ucaldas.edu.co/vetzootec/ index.php/site-map/articles/91-coleccionarticulos-espanol/105-caracterizacionparasitaria-de-la-trucha-arcoiris

6. López J, Salas J. Gómez A, Sanguino W. Estudio gonadal de la sabaleta de la cuenca del Patía (Brycon sp.) como indicador del potencial acuícola. ENTORNOS. 2012; 6(6):1-20. https://revistas.udenar.edu.co/ index.php/reipa/article/view/1514

7. IDEAM. Centro de documentación, Visor Geográfico. [en línea]. Colombia: Instituto de Hidrología, Meteorología y Estudios Ambientales (IDEAM); 2012. http://www. ideam.gov.co/web/ocga/visor-geografico

8. Horwitz W, Latimer G. Oficial Methods of Analysis. 18th. ed. Gaithersburg: AOAC INTERNATIONAL; 2005. http://sutlib2.sut. ac.th/sut contents/H125800.pdf
9. López J. Nutrición y Alimentación Piscícola. 1a. edición. Pasto, Colombia: Editorial Universidad de Nariño; 2014. URL: http:// editorial.udenar.edu.co/?p=2107

10. Vásquez W, Yossa M, Hernández G, Gutiérrez C. Digestibilidad aparente de ingredientes de uso común en la fabricación de raciones balanceadas para tilapia roja híbrida (Oreochromis $s p$ ). Rev Colomb Cienc Pecu. 2010; 23(1):207-216. https:// revistas.udea.edu.co/index.php/rccp/ article/view/324564/20781785

11. Stone F, Hardy R, Shearer K, Scott T. Utilization of fish silage by rainbow trout (Salmo gairdneri). Rev Aquaculture. 1989; 76:109-118. https://doi.org/10.1016/00448486(89)90255-X

12. Peréa C, Garcés Y,Muñoz L, Hoyos J, Gómez J. Economic valuation of silage with fishfarming residues in Oreochromis $s p p$ food. Rev Biotecnología en el Sector Agropecuario y Agroindustrial. 2018; 16(1):43-51. https://revistas.unicauca. edu.co/index.php/biotecnologia/article/ view/1141/935

13. Llanes J, Toledo J, Savón L, Gutiérrez B. Crecimiento de Tilapias rojas Oreochromis mossambicus $\times 0$. niloticus con dietas semihúmedas a base de ensilados de residuos pesqueros. Rev Mundo Pecuario. 2014; 10(2):69-83. http://www.saber.ula.ve/ handle/123456789/39450 